\title{
Standardization of a Radiofrequency Ablation Tool in an Ex-Vivo Porcine Liver Model
}

\author{
Gemma Rossi 1,*®D, Maria Chiara Petrone ${ }^{1}$, Gabriele Capurso ${ }^{1}$, Luca Albarello ${ }^{2}$, \\ Sabrina Gloria Giulia Testoni ${ }^{1}$, Livia Archibugi ${ }^{1}$, Marco Schiavo Lena ${ }^{2}$, Claudio Doglioni ${ }^{2}$ and \\ Paolo Giorgio Arcidiacono ${ }^{1}$ \\ 1 Pancreato-Biliary Endoscopy and Endosonography Division, Pancreas Translational and Clinical Research \\ Center, San Raffaele Scientific Institute IRCCS-Vita Salute San Raffaele University, 20132 Milan, Italy; \\ petrone.mariachiara@hsr.it (M.C.P.); capurso.gabriele@hsr.it (G.C.); \\ testoni.sabrinagloriagiulia@hsr.it (S.G.G.T.); archibugi.livia@hsr.it (L.A.); \\ arcidiacono.paologiorgio@hsr.it (P.G.A.) \\ 2 Department of Pathology, San Raffaele Scientific Institute IRCCS-Vita Salute San Raffaele University, \\ 20132 Milan, Italy; albarello.luca@hsr.it (L.A.); schiavolena.marco@hsr.it (M.S.L.); \\ doglioni.claudio@hsr.it (C.D.) \\ * Correspondence: rossi.gemma@hsr.it; Tel.: +39-02-2643-5509
}

Received: 14 August 2020; Accepted: 16 September 2020; Published: 18 September 2020

check for updates

\begin{abstract}
Background: Preclinical and clinical data about a novel radiofrequency ablation (RFA) system (STARmed Co, Ltd.; Koyang, Korea) designed to be used under endoscopic ultrasound (EUS) control for pancreatic lesion ablation, are limited, obtained with non-standardized procedures and heterogeneous results. The aim of this study is to standardize the RFA procedure of this system in order to define the optimal ablation power and time. (2) Methods: RFA was performed on an ex-vivo porcine liver at different powers (40,30, 20, 10 Watts (W)) and times $(1,3,5,7$, $15 \mathrm{~min}$ ) with a 1-centimeter monopolar electrode (perfused by chilled solution) positioned on the distal tip of a 19-Gauge needle. A blinded expert pathologist histologically analyzed each ablation area. (3) Results: The size of the total macroscopic ablated area was negatively correlated with ablation power $(\mathrm{R}-0.74)$ : the largest was obtained at $10 \mathrm{~W}\left(p=4.7 \times 10^{-4}\right)$ for longer times $(\mathrm{R} 0.92$; $p=8.9 \times 10^{-8}$ ). Central histologic coagulative necrosis did not differ among ablation settings (mean size $3.25 \mathrm{~mm}$ ). External "parenchymal hypochromia" or "diaphanization" resulted the widest at $10 \mathrm{~W}$, for longer times ( $\mathrm{R} 0.8, p=3.6 \times 10^{-4}$ ). (4) Conclusions: The RFA system can produce small sizes of coagulative necrosis, regardless of the setting. Larger areas of diaphanization surrounding the necrosis can be produced at lower powers for longer times.
\end{abstract}

Keywords: radiofrequency ablation; ex-vivo; animal models; EUS; pancreatic lesions

\section{Introduction}

Radiofrequency ablation (RFA) is a minimally invasive technique widely applied in clinical practice for the treatment of parenchymal tumors, obtaining a thermal-induced coagulative necrosis [1,2].

Nevertheless, due to the thermal effect, the application of RFA on pancreatic tumors carries an important risk of injury of the surrounding structures, like the common bile duct, the duodenum and the pancreas itself, with the potential risk of acute pancreatitis. Available probes differ based on their application, whether employed for surgical or endoscopic pancreatic RFA. These are designed to obtain a spherical area of ablation, with an extension influenced by the thermal efficiency of the delivery system and by intrinsic tissue factors, such as tissue impedance or "resistive heating" and the "heat-shrink" effect $[3,4]$. 
A novel RFA system (STARmed Co, Ltd.; Koyang, Korea) is now commercially available, and has been specifically designed to be inserted in an echoendoscope, permitting a mini-invasive ablation of pancreatic lesions under endoscopic ultrasound (EUS) control. The system consists (Figure 1) of a radiofrequency (RF) generator (VIVA generator), a needle (EUSRA: different size, 18 Gauge (G) and $19 \mathrm{G})$ with a monopolar RF electrode positioned on the distal tip $(5,10,15,20,25,30 \mathrm{~mm}(\mathrm{~mm})$ available lengths), and a peristaltic pump permitting the needle perfusion during the ablation with chilled saline solution.

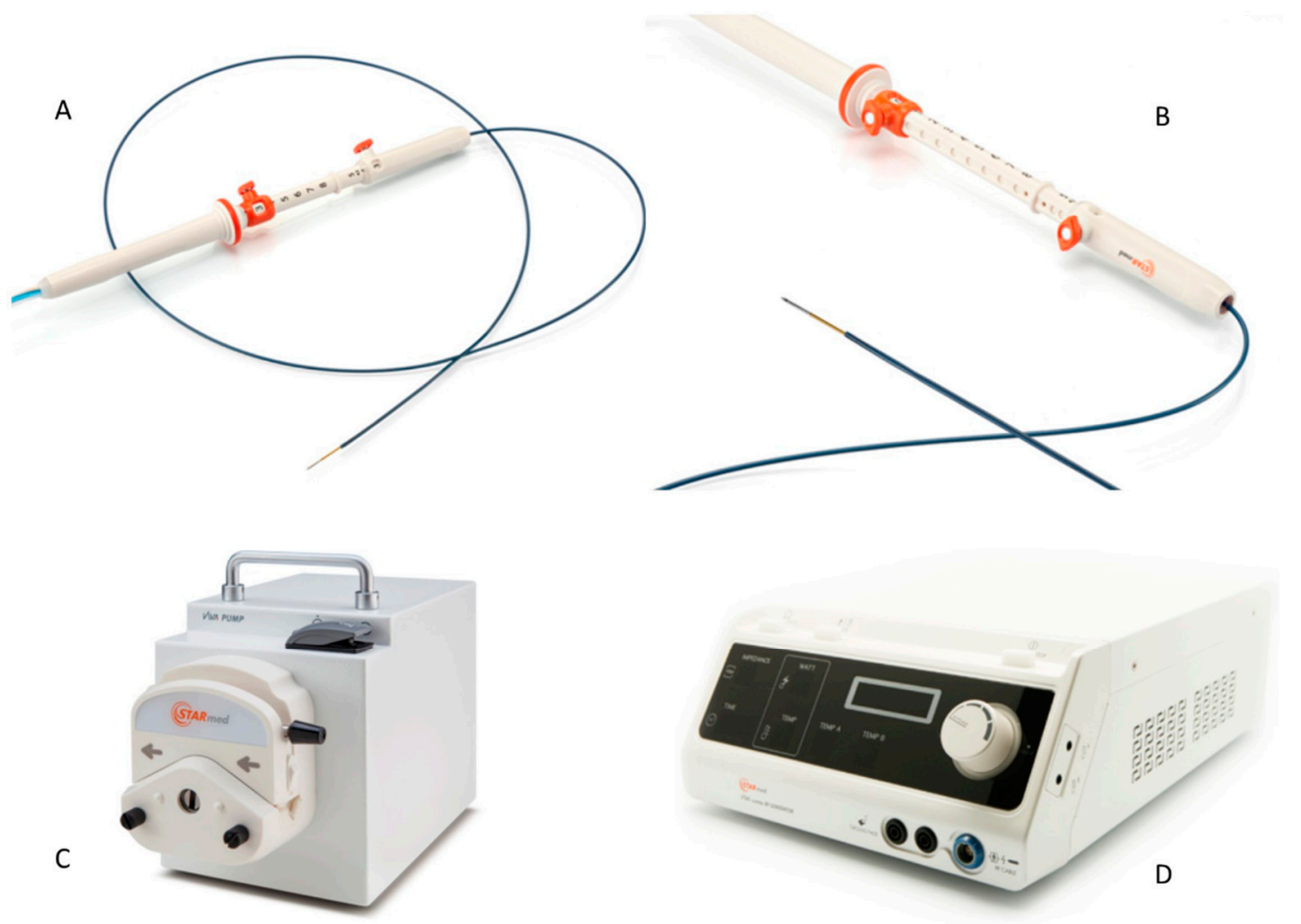

Figure 1. Radiofrequency ablation system (STARMED, Koyang, Korea): (A,B) EUSRA needle and tip (active part), available at different sizes and usable under endoscopic ultrasound guide; (C) peristaltic pump for needle perfusion with chilled solution during thermal ablation; (D) VIVA radiofrequency generator: power can be regulated and time and impedance are continuously monitored during the ablation.

There have been few attempts to apply this RFA system in pre-clinical settings, with few ex-vivo and in-vivo animal studies, and only small case-series reported its use on patients. These studies showed substantial heterogeneity in terms of methods, especially ablation settings (power and time) and subsequent results [5-10]. In particular, the cited study described RFA on few animal (maximum number of 10 adult pigs) or patients (only case-series and case-reports) and are very different in terms of ablation powers (range 20-50 W with one or multiple RFA applications inside the lesions based on the tumor size) and tissue ablated: normal pancreatic parenchyma (in animal studies), pancreatic adenocarcinoma, or neuroendocrine symptomatic tumors (insulinomas). No clinical study described the histological necrosis result after lesion resection (just the pre-clinical in-vivo study described the coagulative necrosis obtained at histology) or performed a standardized imaging analysis with Computed Tomography (CT)-scan or Magnetic Resonance Imaging (MRI) of the central necrosis obtained.

Recently, a prospective multicenter study reported results on a cohort of 17 patients with pancreatic cystic neoplasms and 12 with pancreatic neuroendocrine neoplasms treated with EUS-guided RFA at 
high power $(50 \mathrm{~W})$ with an $18 \mathrm{G}$ needle and 1-centimeter $(\mathrm{cm})$ of active part [11]. Notably, the protocol had to be modified after the first procedures due to the high rate of complications such as pancreatitis and perforation. This further highlights the importance to standardize the conditions of the RFA system on pre-clinical models in order to minimize complications and optimize the benefits of the treatment.

The aim of the present study is therefore to standardize the RFA procedure of this system in the context of an ex-vivo model of porcine liver in order to define the ideal ablation power and ablation time, inducing the maximum size of histological coagulative necrosis.

\section{Materials and Methods}

\subsection{Animal Model}

Different RFA tests were conducted on ex-vivo porcine livers from male animals at least after $48 \mathrm{~h}$ from animal explant, as previously performed for the evaluation of another RFA plus cryoablation probe usable under the EUS guide [12,13]. In particular, in-vivo animal studies were conducted after ex-vivo animal preliminary probe tests. RFA was applied on cubic pieces of hepatic parenchyma (about $5 \times 5 \mathrm{~cm}$ ), cut at the same size before the ablation procedure. The study was a preclinical phase of an ongoing approved research about RFA of human ex-vivo pancreatic solid lesions (pancreatic adenocarcinoma and neuroendocrine tumors; protocol: RFA ex-vivo 2016).

\subsection{RFA System}

The ablation power and time could be set on the RF generator, with tissue impedance, current, and temperature continuously monitored during the procedure. The system could automatically modulate and decrease the power during the ablation if tissue impedance quickly increased or could eventually stop the treatment if the impedance (and relative temperature) raised beyond the safety thresholds (impedance $\geq 500 \mathrm{Ohm}(\Omega)$; temperature $>100^{\circ} \mathrm{C}$ ).

RFA was delivered with a $1 \mathrm{~cm}$-monopolar electrode, positioned on the distal tip of a $19 \mathrm{G}$ needle, $150 \mathrm{~cm}$ in total length, designed to be inserted in an echoendoscope, and connected to the RF generator.

In order to avoid the tissue charring around the probe (due to the thermal damage, inducing the "resistive heating" effect) and maximizing the ablation volume, the needle was cooled and internally perfused by circulating chilled $\left(0^{\circ} \mathrm{C}\right)$ saline solution delivered via a peristaltic pump.

The needle was inserted perpendicularly in each liver sample for an equal length in order to standardize the subsequent macroscopic and microscopic measurement of the diameter of damaged tissue.

\subsection{Ablation Setting}

Different ablation powers were set on the generator to ablate the specimens at $40,30,20$, and 10 Watts $(\mathrm{W})$. Each ablation power was applied respectively on different liver pieces for a time of 1, 3, 5, 7, and $15 \mathrm{~min}$, according to the Fibonacci escalation dose scheme, used in phase I studies [14]. In particular, the total number of specimens treated and analyzed was 40 . Among those, 10 specimens were treated at $40 \mathrm{~W}$ ( 2 pieces for $1 \mathrm{~min}, 2$ for $3 \mathrm{~min}, 2$ pieces for $5 \mathrm{~min}, 2$ for $7 \mathrm{~min}$, and 2 specimens for $15 \mathrm{~min}$ ), 10 specimens at $30 \mathrm{~W}$ (2 pieces for $1 \mathrm{~min}, 2$ for $3 \mathrm{~min}, 2$ pieces for $5 \mathrm{~min}, 2$ for $7 \mathrm{~min}$, and 2 specimens for $15 \mathrm{~min}$ ), 10 specimens at $20 \mathrm{~W}$ ( 2 pieces for $1 \mathrm{~min}, 2$ for $3 \mathrm{~min}, 2$ pieces for $5 \mathrm{~min} 2$ for $7 \mathrm{~min}$, and 2 specimens for $15 \mathrm{~min}$ ), and 10 specimens at $10 \mathrm{~W}$ ( 2 pieces for $1 \mathrm{~min}, 2$ for $3 \mathrm{~min}, 2$ pieces for $5 \mathrm{~min}, 2$ for $7 \mathrm{~min}$, and 2 specimens for $15 \mathrm{~min}$ ).

At the end of the ablation procedure, the specimens (each specimen treated at a certain power and time) were dived in buffered $10 \%$ formalin, labeled with a number, and delivered to a gastrointestinal and pancreato-biliary expert pathologist (LA) blinded about the settings (power and time) applied.

The pathologist sliced the tissue with a sharp blade, perpendicularly respective to the probe entry, and registered the macroscopic and histologic ablation diameters of the midpoint slice (total ablated area and coagulative necrosis core diameters) obtained in each specimen. 


\subsection{Statistics}

The correlation between ablation powers or ablation times and ablated diameters obtained was calculated by linear least squares regression. The relationship strength was evaluated by means of $\mathrm{R}$ index and relative $p$-values. $p$-values were considered statistically significant if $<0.05$. The Microsoft excel program and a dedicated statistic software (Medcalc 12.1, MedCalc Software Ltd., Ostend, Belgium) were used for the analysis.

\section{Results}

RFA produced a macroscopic spherical ablated area, consisting of two different zones: a central dark ring around the needle insertion point (histologically related to a coagulative necrosis) and an external ring of "parenchymal hypochromia" or "diaphanization".

\subsection{Total Ablated Area}

The total macroscopic ablated area size was negatively correlated with the employed ablation power $(40,30,20,10 \mathrm{~W})(\mathrm{R}-0.74)$. The maximum size of the ablated area was obtained employing the minimal power of $10 \mathrm{~W}\left(p=4.7 \times 10^{-4}\right)$, as shown in Figure 2 .

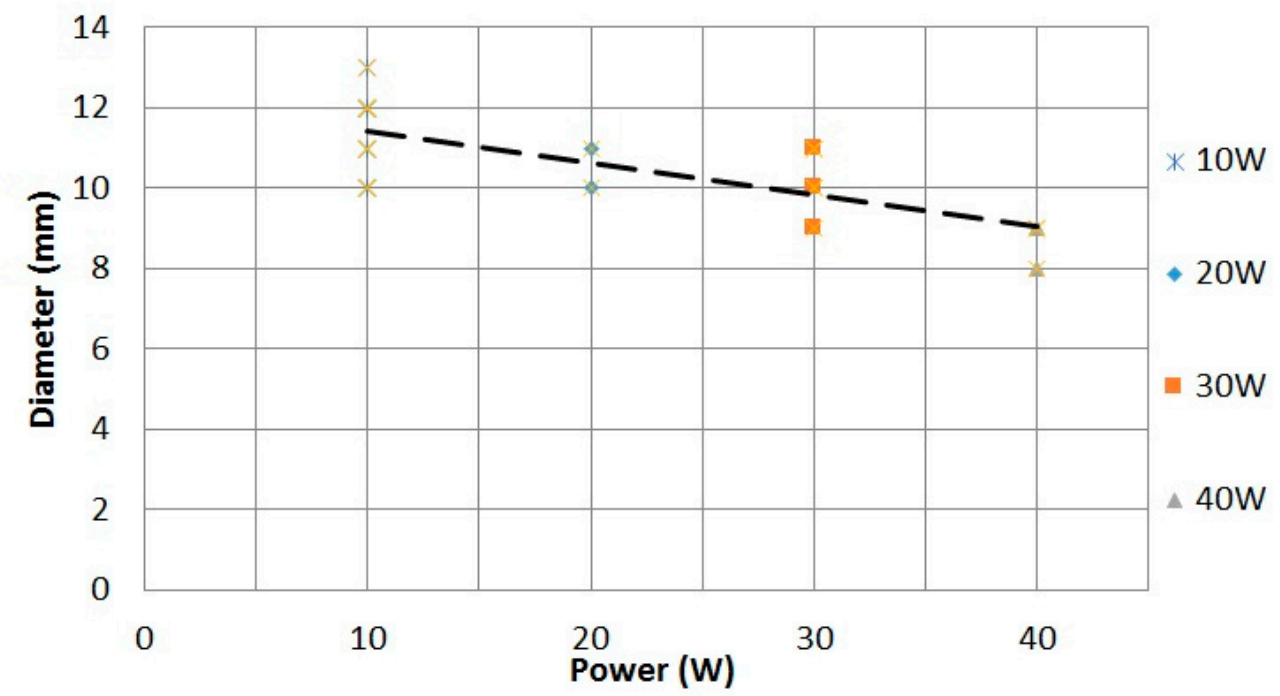

Figure 2. Macroscopic ablated area diameters (millimeters) and powers (10, 20, 30, $40 \mathrm{~W})$. Maximum size of macroscopic ablated area after radiofrequency ablation was obtained at $10 \mathrm{~W}$.

Indeed, a major carbonization effect at the needle-liver interface was evident at the higher powers $(40,30,20 \mathrm{~W})$ in comparison to $10 \mathrm{~W}$, thus limiting the heat diffusion. The analysis of ablation parameters (impedance, temperature, current, power, time) confirmed that at $10 \mathrm{~W}$, the tissue temperature was maintained below the safety value of $100{ }^{\circ} \mathrm{C}$, permitting an effective and larger ablation area, finally avoiding the tissue charring (Figure 3). 


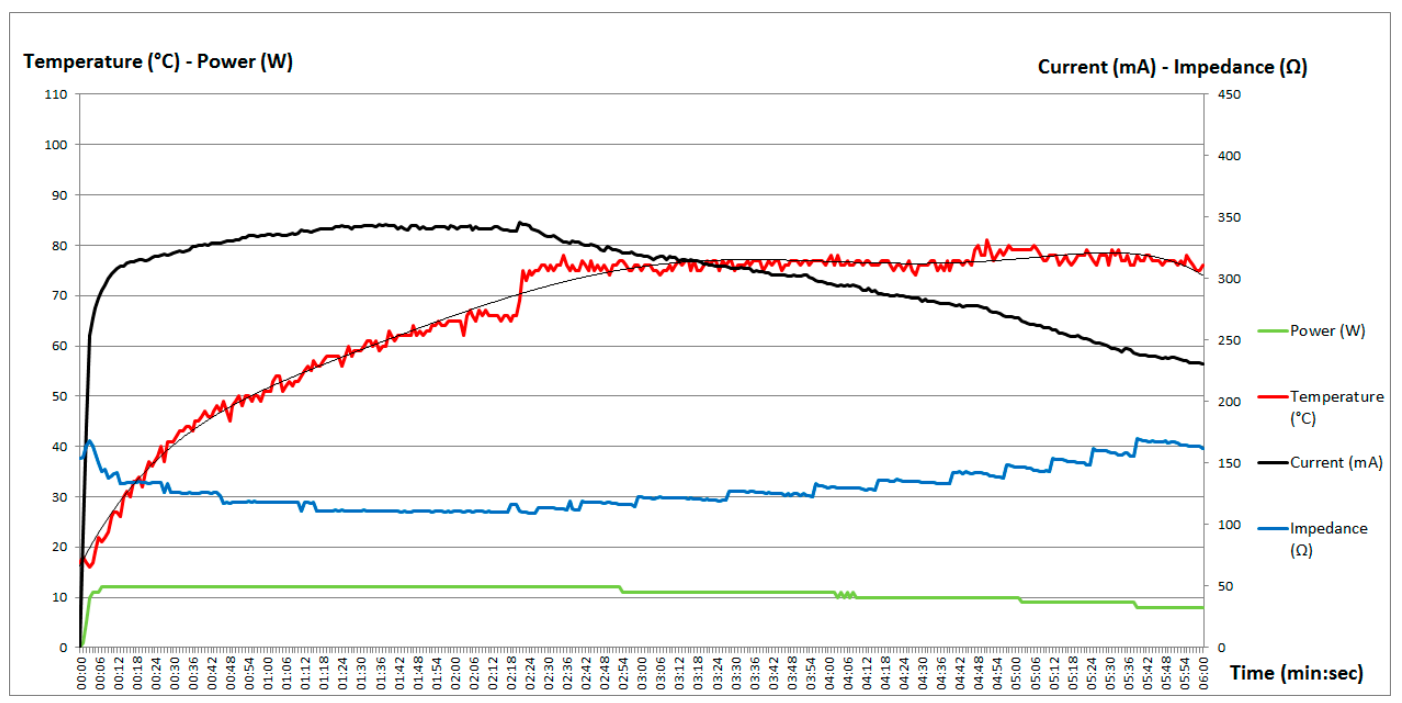

Figure 3. Ablation parameters analysis (impedance, temperature, current, power, time) at $10 \mathrm{~W}$. $X$-axis represents ablation time, $Y$-axis temperature, power, current, and impedance applied by the system. Temperature ( $Y$-axis on the left side of the graph) was always maintained below the safety value of $100{ }^{\circ} \mathrm{C}$ during the ablation, avoiding the tissue charring and therefore allowing an "effective" ablation treatment.

As far as regarding the length of treatments in terms of minutes, the macroscopic analysis of treated specimens at $10 \mathrm{~W}$ for $1,3,5,7$, and $15 \mathrm{~min}$ showed a positive linear correlation among ablation times and ablation area diameters ( $\left.0.92 ; p=8.9 \times 10^{-8}\right)$. Figure 4 shows the increased delivered energy in hepatic tissue with ablation times at $10 \mathrm{~W}$.

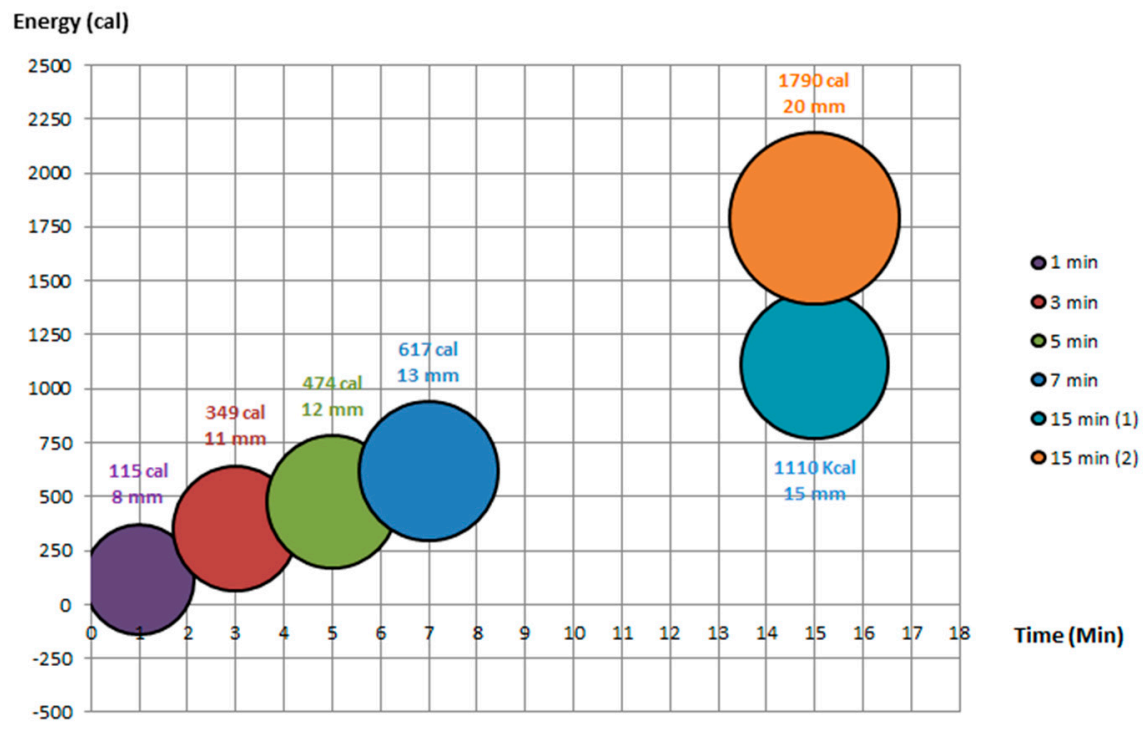

Figure 4. Increased delivered energy ( $Y$-axis) in hepatic tissue with ablation times ( $X$-axis) at $10 \mathrm{~W}$ of ablation power. Increasing the ablation time, the energy ("cal" above circles) increases, as well as the ablation area obtained ("mm" above the circle) after treatment.

\subsection{Area of Coagulative Necrosis}

Macroscopically, the size of the "dark ring" around the needle insertion point was not different among samples treated with different ablation powers and ablation times. 
The histological analysis confirmed these data: the size of the central coagulative necrosis area was not influenced by the different ablation powers $(\mathrm{R}-0.24 ; p=0.35)$ and ablation times, consisting in few millimeters (mean value $3.25 \mathrm{~mm}$ ) as shown in Figure 5.

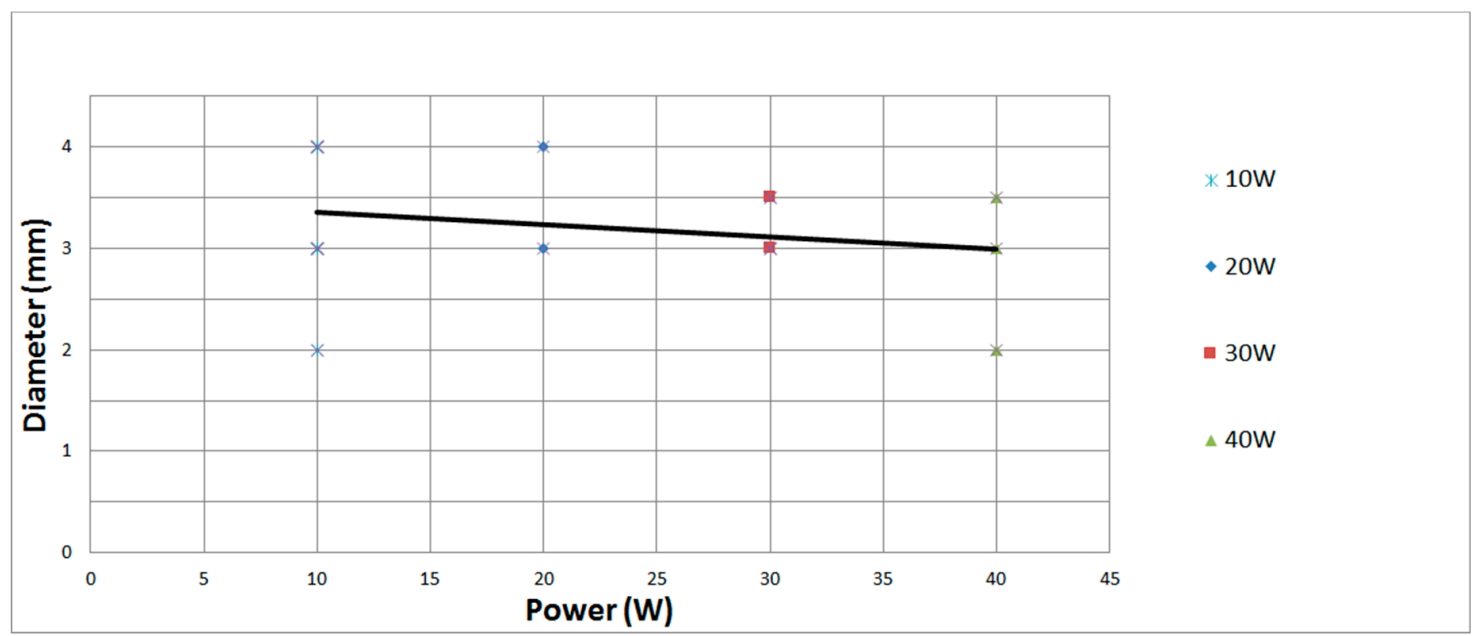

Figure 5. Microscopic necrosis at different ablation powers (10, 20, 30, $40 \mathrm{~W})$. Central coagulative necrosis seen at histology ( $Y$-axis) was not significantly different among the ablation powers applied (X-axis).

\subsection{Diaphanization Area}

At microscopic pathologic evaluation, there were some differences in terms of size and aspect of the external "hypochromia" or "diaphanization" parenchymal area around the central necrotic core between the higher powers $(40,30,20 \mathrm{~W}$ ) and $10 \mathrm{~W}$ (Figure 6).

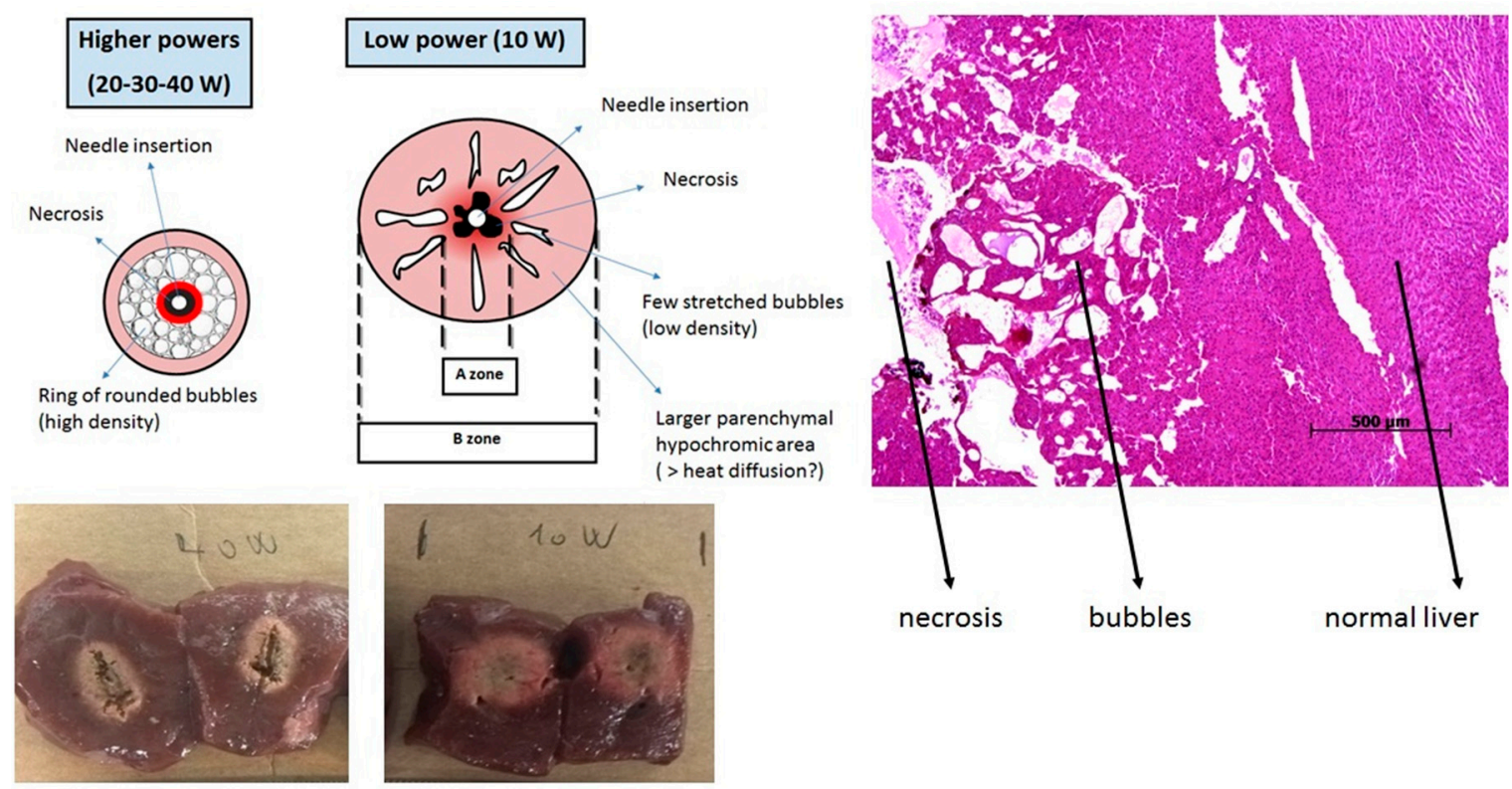

Figure 6. Macroscopic and histologic ablated areas aspect at different powers. Specimens in photos represent the macroscopic aspect of different ablation powers applied (see the differences between higher $(40 \mathrm{~W})$ and lower $(10 \mathrm{~W})$ powers) and schematic drawings represent the histologic aspect of respective specimens at high $(40 \mathrm{~W})$ and low $(10 \mathrm{~W})$ powers. Hematoxylin and eosin staining on the tissue section shows the histologic aspect of the different zones obtained after the radiofrequency ablation (coagulative necrosis-air bubbles limiting the thermal ablation diffusion and finally the external normal hepatic parenchyma). 
Higher powers produced a central necrosis surrounded by a relatively small ring of rounded and dense bubbles of air, which probably limited the heat diffusion, resulting in a limited external ring of "diaphanization".

On the contrary, RFA at $10 \mathrm{~W}$ permitted the best thermal diffusion (due to more stable parameters during the ablation), producing few and stretched air bubbles around the small central necrosis core and a wide external "parenchymal hypochromia" ring. This "parenchymal hypochromia" was related at histology to a cytoplasmic hypocromia ("diaphanization") in hepatocytes, not related to a clear necrosis but to a possible initial damage.

A nearly linear positive ( $\mathrm{R}$ 0.8) and significant correlation $\left(p=3.6 \times 10^{-4}\right)$ was histologically confirmed among parenchymal hypochromia diameters and ablation times at $10 \mathrm{~W}$ (Figure 7).

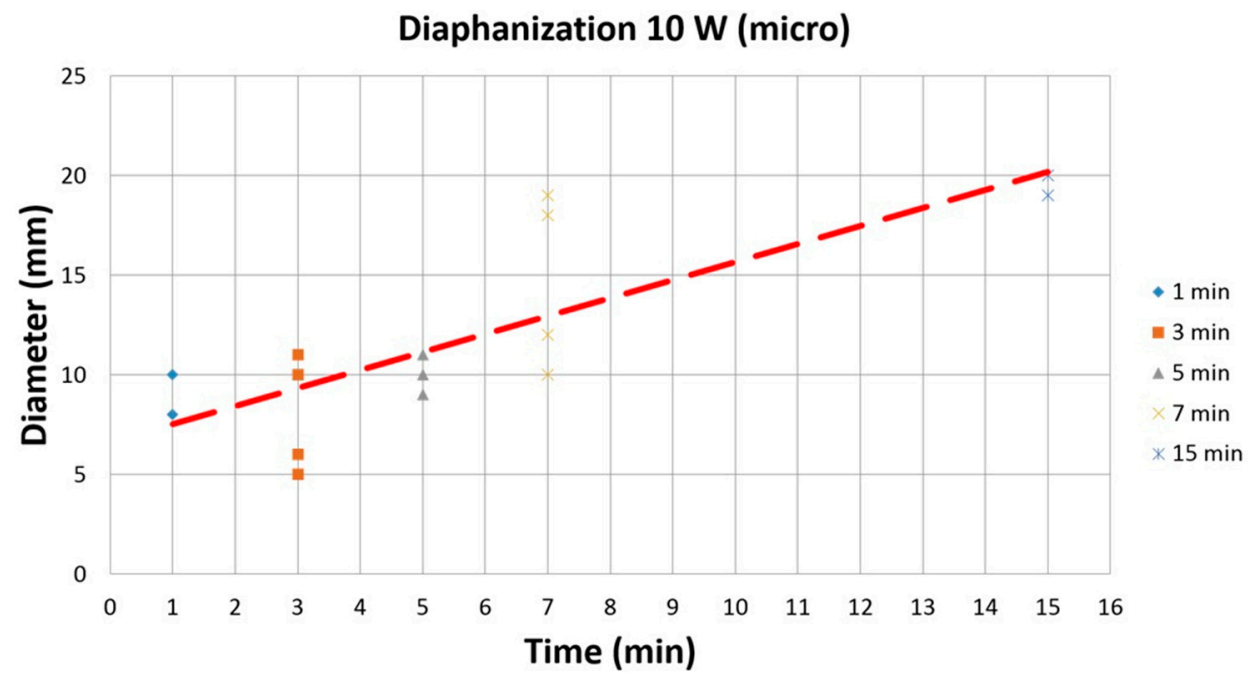

Figure 7. Histologic "parenchymal hypochromia" diameters and ablation times at $10 \mathrm{~W}$. Parenchymal hypochromia diameter $(Y$-axis) increases linearly with ablation time ( $X$-axis).

\section{Discussion}

RFA is becoming a valuable tool in the management of many parenchymal tumors, particularly in primary and metastatic hepatic lesions [15].

EUS-guided RFA of pancreatic tumors is increasingly investigated as a potentially useful technique, offering the best combination of a real-time imaging guidance, a precise electrode localization with a minimal invasiveness. Preliminarily to a clinical application and investigation, such techniques need pre-clinical studies in order to standardize the conditions to obtain an optimal treatment and possibly avoid complications.

Few pre-clinical studies have investigated other RFA probes before. In an ex-vivo study [16] on porcine liver with a different EUS-guided RFA probe (Habib EUS-RFA probe-EMcision Ltd., London, UK), ablation was performed with different powers and times, and the obtained macroscopic and microscopic ablation areas were recorded. The maximal ablation area $(8 \mathrm{~mm}$ in diameter and $21 \mathrm{~mm}$ in length) was obtained at $10 \mathrm{~W}$ for $90 \mathrm{~s}$ (s). Higher powers induced shorter ablation diameters due to the charring of hepatic tissue around a RFA probe with a smaller caliber (1 French smaller compared to our $19 \mathrm{G}$ system).

Ex-vivo animal and other pre-clinical studies were conducted also to investigate the possible role of endoscopic guided-RFA of biliary lesions with bipolar probes [17] and resulted fundamentally to define the correct ablation setting on the basis of the target area.

Previous pre-clinical experiences with the specific RFA system investigated in the present study applied different settings (ablation power and times), starting from high ablation powers [5-7]. The first animal study [5] applied this kind of ablation in-vivo in 10 pancreas of adult pigs with a setting of $50 \mathrm{~W}$ 
for $5 \mathrm{~min}$ ( $50 \mathrm{~W}$ was chosen on the basis of previous ex-vivo tests on bovine liver). The well-demarcated area of coagulative necrosis was obtained after the ablation, distinguished from healthy pancreatic parenchyma by a fibrotic peripheral rim. No histological evaluation of the ablated areas were reported except for the macroscopic one (mean diameter of ablation $23 \pm 6.9 \mathrm{~mm}$ ). In three pigs, a retroperitoneal fibrosis or adhesions were observed.

When compared to these previous RFA experiences, the present results, instead, suggest that a lower power maintained for a longer time allows optimal effects possibly with a limited risk of complications. In a recent human experience [9], eight patients with locally advanced pancreatic cancers were treated with EUS-RFA (EUSRA needle $18 \mathrm{G}$ in caliber; electrode $1 \mathrm{~cm}$ in length) at $30 \mathrm{~W}$ of power and possibly a repeated RFA application if needed, with multiple passes inside the lesions. Ablation time was not previously determined because the treatment was dependent on the rise of tissue impedance, with an automatic stop of the generator beyond a certain threshold. The final mean ablation time of the pancreatic cancer ablations was $58 \mathrm{~s}$. A CT scan was performed at $24 \mathrm{~h}$ for each patient. A CT scan taken one month after RFA showed a mean of $30 \%$ of "thermal induced" ablation area in the tumors.

Scopelliti et al. [10] reported similar results in a case-series, applying EUS-RFA (EUSRA needle $18 \mathrm{G}$ in a caliber of $-1 \mathrm{~cm}$ in length for the active part) in 10 patients with locally advanced pancreatic adenocarcinoma. Larger lesions $(>3 \mathrm{~cm}$ ) were treated at $30 \mathrm{~W}$ of power and smaller ones were treated at $20 \mathrm{~W}$, with a single or multiple (2) needle passes. These settings were established on the basis of their previous experience in open surgery. RFA delivery was automatically stopped by the system when a sharp rise in electric impedance occurred above a certain threshold $(>500 \Omega)$. EUS-RFA was feasible and safe and a demarcated "hypodense ablated area" was observed inside the cancers at 7-day and 30-day CT scans in all cases (mean diameter at 7-day CT scan: $28 \mathrm{~mm} \pm 14$ standard deviation; size of the ablated area at the 30-day CT scan unclear).

In those series $[9,10]$, the authors set the ablation powers at a lower threshold and assessed the efficacy of treatment through a non-standardized radiological analysis in order to quantify the damage in the lesions.

In a recent prospective multicenter study [11], pancreatic cystic lesions or pancreatic neuroendocrine neoplasms were treated at higher powers $(50 \mathrm{~W})$ with a relatively high rate of complications, particularly in the absence of prophylaxis for acute pancreatitis or infection. Moreover, one patient developed a pancreatic duct stenosis after the treatment.

Our experience confirms that RFA is effective at relatively low powers. A larger parenchymal hypochromia area was obtained at $10 \mathrm{~W}$ with a longer ablation time due to a low and more stable impedance during the ablation, avoiding tissue charring at liver-needle interface and permitting a better thermal diffusion. Nevertheless the so-called "parenchymal hypochromia" zone was histologically related to a cytoplasmic hypochromia in hepatocytes, without evidence of a final necrosis. This is a preliminary ex-vivo animal study and the in-vivo evolution of this "damaged but not killed" ablated zone should be assessed in the future. One might speculate that depending on the effect of vascularization and immune response this damaged area might recover or evolve into necrosis.

Indeed, in the present ex-vivo study, RFA determined limited histological diameters of coagulative necrosis around the needle insertion point, regardless of ablation times and ablation powers applied. Necrosis, irrespective to the type, is the final aim of a local ablative treatment in order to obtain a subsequent fibrosis and malignant cells destruction.

On the basis of the limited sizes of coagulative necrosis areas obtained in our preliminary experience, it is likely that the optimal indication for this probe could be to treat relatively small (millimeters) pancreatic lesions or to act as co-adjuvant for other ablative local therapies, able to treat larger masses, inducing larger necrotic areas such as the Hybrid Therm Probe (HTP) [12,13,18-20].

Notably, Barret et al. [21] confirmed in a recent pre-clinical in-vivo animal study comparing the two available EUS-RFA systems on the market (this specific system and Habib EUS-RFA probe) that 
EUS-guided RFA can obtain relatively small sizes of coagulative necrosis on porcine liver and pancreas (maximum of $3.8 \pm 0.4 \mathrm{~mm}$ ).

The strength of the present study is the rigorous standardization of the procedures at different powers and time-points and the careful pathological observation of the obtained effects. Among the limitations are the physical and histological differences between the treated healthy hepatic parenchyma and the possible future targets of EUS-guided RFA, such as pancreatic adenocarcinoma which is usually a stiffer lesion. Differences between healthy hepatic parenchyma and pancreatic adenocarcinoma tissue were considered in the design of the study but the idea of this preclinical study was to investigate the optimal power settings able to create the largest necrotic area and then to evaluate these parameters on a subsequent ex-vivo pathological human pancreatic tissue (solid lesions as pancreatic adenocarcinoma or neuroendocrine tumors).

Furthermore, future studies should assess the possible role of RFA in locally advanced pancreatic cancer as an addition to chemotherapy in light of its possible immuno-modulatory role [22,23], especially for non-surgical patients.

\section{Conclusions}

In conclusion, the employed RFA system can produce small sizes of coagulative necrosis, regardless of the setting (power and time) applied. Nevertheless, the system can produce larger "parenchymal hypochromia" zones surrounding the necrosis at lower powers for longer times, due to a better thermal diffusion. Future studies are needed to assess the in-vivo evolution of this "parenchymal hypochromia" areas and the ex-vivo effect of RFA with this system on pancreatic solid lesions.

Author Contributions: Conceptualization: P.G.A., M.C.P., and G.R. Formal analysis: M.C.P., G.R., and L.A. (Luca Albarello). Investigation: M.C.P., G.R., S.G.G.T., L.A. (Luca Albarello), and M.S.L. Data curation: G.R. and L.A. (Luca Albarello). Writing—original draft preparation: G.R., M.C.P., and L.A. (Livia Archibugi). Writing一review and editing: G.R., M.C.P., and G.C. Supervision: P.G.A. and C.D. Project administration: P.G.A. All authors have read and agreed to the published version of the manuscript.

Funding: This research received no external funding.

Acknowledgments: We'd like to thank biomedical engineer Leonardo Portella for the technical help.

Conflicts of Interest: The authors declare no conflict of interest.

\section{References}

1. Paiella, S.; Salvia, R.; Ramera, M.; Girelli, R.; Frigerio, I.; Giardino, A.; Allegrini, V.; Bassi, C. Local Ablative Strategies for Ductal Pancreatic Cancer (Radiofrequency Ablation, Irreversible Electroporation): A Review. Gastroenterol. Res. Pract. 2016, 2016, 4508376. [CrossRef]

2. Chu, K.F.; Dupuy, D.E. Thermal ablation of tumours: Biological mechanisms and advances in therapy. Nat, Rev, Cancer, 2014, 14, 199-208. [CrossRef] [PubMed]

3. Wright, A.S.; Sampson, L.A.; Warner, T.F.; Mahvi, D.M.; Lee, F.T., Jr. Radiofrequency versus microwave ablation in a hepatic porcine model. Radiology 2005, 236, 132-139. [CrossRef] [PubMed]

4. Signoretti, M.; Valente, R.; Repici, A.; Fave, G.D.; Capurso, G.; Carrara, S. Endoscopy-guided ablation of pancreatic lesions: Technical possibilities and clinical outlook. World J. Gastrointest. Endosc. 2017, 9, 41-54. [CrossRef]

5. Kim, H.J.; Seo, D.W.; Hassanuddin, A.; Kim, S.-H.; Chae, H.J.; Jang, J.W.; Park, D.H.; Lee, S.S.; Lee, S.-K.; Kim, M.-H. EUS-guided radiofrequency ablation of the porcine pancreas. Gastrointest. Endosc. 2012, 76, 1039-1043. [CrossRef] [PubMed]

6. Song, T.J.; Seo, D.W.; Lakhtakia, S.; Reddy, N.; Oh, D.W.; Park, D.H.; Lee, S.S.; Lee, S.K.; Kim, M.-H. Initial experience of EUS-guided radiofrequency ablation of unresectable pancreatic cancer. Gastrointest. Endosc. 2016, 83, 440-443. [CrossRef] 
7. Lakhtakia, S.; Ramchandani, M.; Galasso, D.; Gupta, R.; Venugopal, S.; Kalpala, R.; Reddy, D.N. EUS-guided radiofrequency ablation for management of pancreatic insulinoma by using a novel needle electrode (with videos). Gastrointest. Endosc. 2016, 83, 234-239. [CrossRef]

8. Armellini, E.; Crinò, S.F.; Ballarè, M.; Occhipinti, P. Endoscopic ultrasound-guided radiofrequency ablation of a pancreatic neuroendocrine tumor. Endoscopy 2015, 47. [CrossRef]

9. Crinò, S.F.; D’Onofrio, M.; Bernardoni, L.; Frulloni, L.; Iannelli, M.; Malleo, G.; Paiella, S.; Larghi, A.; Gabbrielli, A. EUS-guided Radiofrequency Ablation (EUS-RFA) of Solid Pancreatic Neoplasm Using an 18-gauge Needle Electrode: Feasibility, Safety, and Technical Success. J. Gastrointest. Liver Dis. 2018, 27, 67-72. [CrossRef]

10. Scopelliti, F.; Pea, A.; Conigliaro, R.; Butturini, G.; Frigerio, I.; Regi, P.; Giardino, A.; Bertani, H.; Paini, M.; Pederzoli, P.; et al. Technique, safety, and feasibility of EUS-guided radiofrequency ablation in unresectable pancreatic cancer. Surg. Endosc. 2018, 32, 4022-4028. [CrossRef]

11. Barthet, M.; Giovannini, M.; Lesavre, N.; Boustiere, C.; Napoleon, B.; Koch, S.; Gasmi, M.; Vanbiervliet, G.; Gonzalez, J.-M. Endoscopic ultrasound-guided radiofrequency ablation for pancreatic neuroendocrine tumors and pancreatic cystic neoplasms: A prospective multicenter study. Endoscopy 2019, 51, 836-842. [CrossRef] [PubMed]

12. Carrara, S.; Arcidiacono, P.G.; Albarello, L.; Addis, A.; Enderle, M.D.; Boemo, C.; Campagnol, M.; Ambrosi, A.; Doglioni, C.; Testoni, P.A. Endoscopic ultrasound-guided application of a new hybrid cryotherm probe in porcine pancreas: A preliminary study. Endoscopy 2008, 40, 321-326. [CrossRef] [PubMed]

13. Carrara, S.; Arcidiacono, P.G.; Albarello, L.; Addis, A.; Enderle, M.D.; Boemo, C.; Neugebauer, A.; Campagnol, M.; Doglioni, C.; Testoni, P.A. Endoscopic ultrasound-guided application of a new internally gas cooled radiofrequency ablation probe in the liver and spleen of an animal model: A preliminary study. Endoscopy 2008, 40, 759-763. [CrossRef] [PubMed]

14. Edler, L. Statistical requirements of phase I studies. Onkologie 1990, 13, 90-95. [CrossRef]

15. Shibata, T.; Niinobu, T.; Ogata, N. Comparison of the effects of in-vivo thermal ablation of pig liver by microwave and radiofrequency coagulation. J. Hepatobiliary Pancreat. Surg. 2000, 7, 592-598. [CrossRef]

16. Rustagi, T.; Gleeson, F.C.; Abu Dayyeh, B.K.; Topazian, M.D.; Levy, M.J. Evaluation of Effects of Radiofrequency Ablation of Ex vivo Liver Using the 1-Fr Wire Electrode. J. Clin. Gastroenterol. 2018, 52, 168-171. [CrossRef]

17. Itoi, T.; Isayama, H.; Sofuni, A.; Itokawa, F.; Tamura, M.; Watanabe, Y.; Moriyasu, F.; Kahaleh, M.; Habib, N.; Nagao, T.; et al. Evaluation of effects of a novel endoscopically applied radiofrequency ablation biliary catheter using an ex-vivo pig liver. J. Hepatobiliary Pancreat. Sci. 2012, 19, 543-547. [CrossRef]

18. Carrara, S.; Petrone, M.C.; Testoni, P.A.; Arcidiacono, P.G. Tumors and new endoscopic ultrasound-guided therapies. World J. Gastrointest. Endosc. 2013, 5, 141-147. [CrossRef]

19. Petrone, M.C.; Arcidiacono, P.G.; Carrara, S.; Albarello, L.; Enderle, M.D.; Neugebauer, A.; Boemo, C.; Doglioni, C.; Testoni, P.A. US-guided application of a new hybrid probe in human pancreatic adenocarcinoma: An ex vivo study. Gastrointest. Endosc. 2010, 71, 1294-1297. [CrossRef]

20. Arcidiacono, P.G.; Carrara, S.; Reni, M.; Petrone, M.C.; Cappio, S.; Balzano, G.; Boemo, C.; Cereda, S.; Nicoletti, R.; Enderle, M.D.; et al. Feasibility and safety of EUS-guided cryothermal ablation in patients with locally advanced pancreatic cancer. Gastrointest. Endosc. 2012, 76, 1142-1151. [CrossRef]

21. Barret, M.; Leblanc, S.; Rouquette, A.; Chaussade, S.; Terris, B.; Prat, F. EUS-guided pancreatic radiofrequency ablation: Preclinical comparison of two currently available devices in a pig model. Endosc. Int. Open 2019, 7, E138-E143. [CrossRef] [PubMed]

22. Haen, S.P.; Pereira, P.L.; Salih, H.R.; Rammensee, H.-G.; Gouttefangeas, C. More than just tumor destruction: Immunomodulation by thermal ablation of cancer. Clin. Dev. Immunol. 2011, 2011, 160250. [CrossRef] [PubMed]

23. Giardino, A.; Innamorati, G.; Ugel, S.; Perbellini, O.; Girelli, R.; Frigerio, I.; Regi, P.; Scopelliti, F.; Butturini, G.; Paiella, S.; et al. Immunomodulation after radiofrequency ablation of locally advanced pancreatic cancer by monitoring the immune response in 10 patients. Pancreatology 2017, 17, 962-966. [CrossRef] [PubMed]

(C) 2020 by the authors. Licensee MDPI, Basel, Switzerland. This article is an open access article distributed under the terms and conditions of the Creative Commons Attribution (CC BY) license (http://creativecommons.org/licenses/by/4.0/). 